\title{
Effects of milking stall dimensions on behavior of dairy cows during milking in different milking parlor types
}

\author{
Y. Gómez, ${ }^{*}{ }^{1}$ M. Terranova, $\$ \S$ M. Zähner, ${ }^{*}$ E. Hillmann, $\dagger$ and P. Savary* \\ ${ }^{*}$ Research Group Work, Building and System Assessment, Research Institute Agroscope ISS, 8356 Ettenhausen, Switzerland \\ †Ethology and Animal Welfare Unit, and \\ $\ddagger$ Animal Nutrition, Department of Environmental System Sciences, ETH Zürich, 8092 Zürich, Switzerland \\ $\S$ Livestock Systems Engineering, Institute of Agricultural Engineering, Faculty of Agricultural Sciences, University of Hohenheim, \\ 70599 Stuttgart, Germany
}

\begin{abstract}
Dairy cow body size has increased over time because of breeding selection for higher milk yield, but milking stall dimensions have never been adjusted and are based on the practical experience of milking-machine manufacturers and advisory institutions. Narrow, limited milking stall dimensions might lead to behavioral changes during milking due to lack of comfort. The aim of this study was to examine the current space allowance in milking stalls on dairy farms and assess the effect of space allowance on cow behavior during milking. On 15 Swiss dairy farms, we measured clear milking stall dimensions and cow body dimensions. We calculated space ratios for length $\left(\mathrm{SR}_{\text {length }}\right)$ and width $\left(\mathrm{SR}_{\text {width }}\right)$ by dividing the milking stall length or width by cow body length or belly width, respectively. When the space ratio was $>1$, we assumed that the body length or width of cow was smaller than the milking stall length or width. On each farm, 10 healthy cows were chosen for behavioral observation during 1 evening milking. We recorded rumination, elimination, and latency to enter the milking stall by direct observation. Hind leg activity was recorded using acceleration loggers. Data were analyzed using general linear mixedeffects models with farm as a random effect. Due to a strong collinearity between $\mathrm{SR}_{\text {width }}$ and $\mathrm{SR}_{\text {length }}$, we chose $\mathrm{SR}_{\text {length }}$ for further analysis, because it is based on skeletal characteristics. The $\mathrm{SR}_{\text {length }}$ was smallest in side-by-side parlors $(1.07 \pm 0.01)$ and largest in tandem parlors $(1.18 \pm 0.01)$. More cows had a tendency to ruminate with increasing $\mathrm{SR}_{\text {length }}$ (odds ratio: 1.8). None of hind leg activity, maximum peaks of hind leg accelerations, or latency to enter the milking stall were significantly affected by $\mathrm{SR}_{\text {length }}$. Latency to enter the milking stall was longer for group milking parlors
\end{abstract}

Received June 10, 2016.

Accepted October 27, 2016.

${ }^{1}$ Corresponding author: yamenah.gomez@agroscope.admin.ch (side-by-side: $44.0 \pm 3.2 \mathrm{~s}$; herringbone: $34.3 \pm 2.9 \mathrm{~s}$ ) than for tandem parlors $(19.0 \pm 2.7 \mathrm{~s})$. Milking parlor type had no effect on hind leg activity, maximum peaks of hind leg accelerations or rumination. The $\mathrm{SR}_{\text {length }}$ affected rumination behavior to some extent, indicating that cow comfort was positively affected by larger milking stall length. Because cow comfort is important for good milking performance, further investigations of milking stall dimensions for cow comfort and thus welfare are needed. Furthermore, the results showed that parlor type affected cow behavior, irrespective of $\mathrm{SR}_{\text {length }}$, making future research necessary to identify the factors leading to this effect of parlor type.

Key words: milking stall dimension, cow body dimension, space ratio, space allowance, behavioral change

\section{INTRODUCTION}

Breeding selection for high milk yield has caused the body dimensions of dairy cows to increase over the past decades due to genetic correlations between height at withers and milk yield and height at withers and chest depth (Rauw et al., 1998; Petermann, 2005; Schönmuth and Löber, 2006; Rodenburg and Turner, 2012). Between 1967 and 1987, the diagonal body length of Holstein dairy cows increased by $13.9 \mathrm{~cm}$, according to analyses of breeding history (Grothe, 2007; Brade and Brade, 2013). Rudolphi (2008) had similar observations for Holstein cows between 1988 and 2005, with an increase in weight of $20 \%$ and in height of $8 \%(+11 \mathrm{~cm})$.

Minimum requirements and recommendations indicate that feeding and lying areas should be adapted to the size or weight of the animals, or both (Defra, 2003; Nordlund and Cook, 2003; Flaba et al., 2004; Wechsler, 2005; Eilers, 2007). With respect to milking, no studies have dealt with the effects of milking stall dimensions on cow behavior, but small space allowance in waiting areas has been found to increase heart rate and agonistic behavior, and these effects were still detectable during the milking (Irrgang et al., 2015). 
To our knowledge, no research-based recommendations for milking stall dimensions are available. In the milking parlor, the main focus is on milk yield and efficiency of milking (i.e., on the number of milked cows per hour; Smith et al., 1997; Fernández et al., 2009; O'Brien et al., 2012) or on ergonomic aspects of milking (Douphrate et al., 2013; Cockburn et al., 2015). Recommendations for the construction of milking parlors are usually based on the practical experience of milkingmachine manufacturers and advisory institutions.

Additionally, parlor type might affect behavior during milking, as found by Savary et al. (2014). In tandem parlors, cows are enclosed to their full length, but in group milking parlors they are enclosed only from shoulder to tail, with free space for the neck and head. Furthermore, in group milking parlors, cows experience physical contact with neighboring cows and may not be able to keep preferred individual distances. This might cause a reduction in cow comfort during milking.

With reference to the lack of scientific background information for milking stall dimensions, these facts highlight the importance of investigating the effect of space allowances in milking stalls in different milking parlors on the well-being of cows.

The aim of this study was to investigate milking stall dimensions on dairy farms in relation to the body dimensions of the cows. Specifically, we examined the effect of space allowance in milking stalls on the behavior of cows during milking. Previous studies used low rumination activity, high elimination rates, high hind leg activity such as stepping and kicking behavior, long latency to enter the milking stall and longer duration of milking as indicators of a stress or avoidance response in cows, or both (Hopster et al., 1998; Stefanowska et al., 2000; Rushen et al., 2001; Hagen et al., 2004; Herskin et al., 2004; Rousing et al., 2004; Bristow and Holmes, 2007). We predicted that low space allowance would cause a decrease in rumination, a higher probability of elimination, an increase in hind leg activity, and a longer latency to enter the milking stall.

\section{MATERIALS AND METHODS}

This study was conducted in March 2015 on 15 Swiss dairy farms (5 per milking parlor type; Table 1 ). In total, we measured 444 cows of 2 main breeds, and we collected behavioral data during 1 evening milking of 10 focus cows per farm. All animal experiments conformed to Swiss animal welfare legislation and were ethics-approved (TG 05/2014).

\section{Selection of Farms and Cows}

Only farms that satisfied 7 predefined criteria for housing and management were accepted into this study

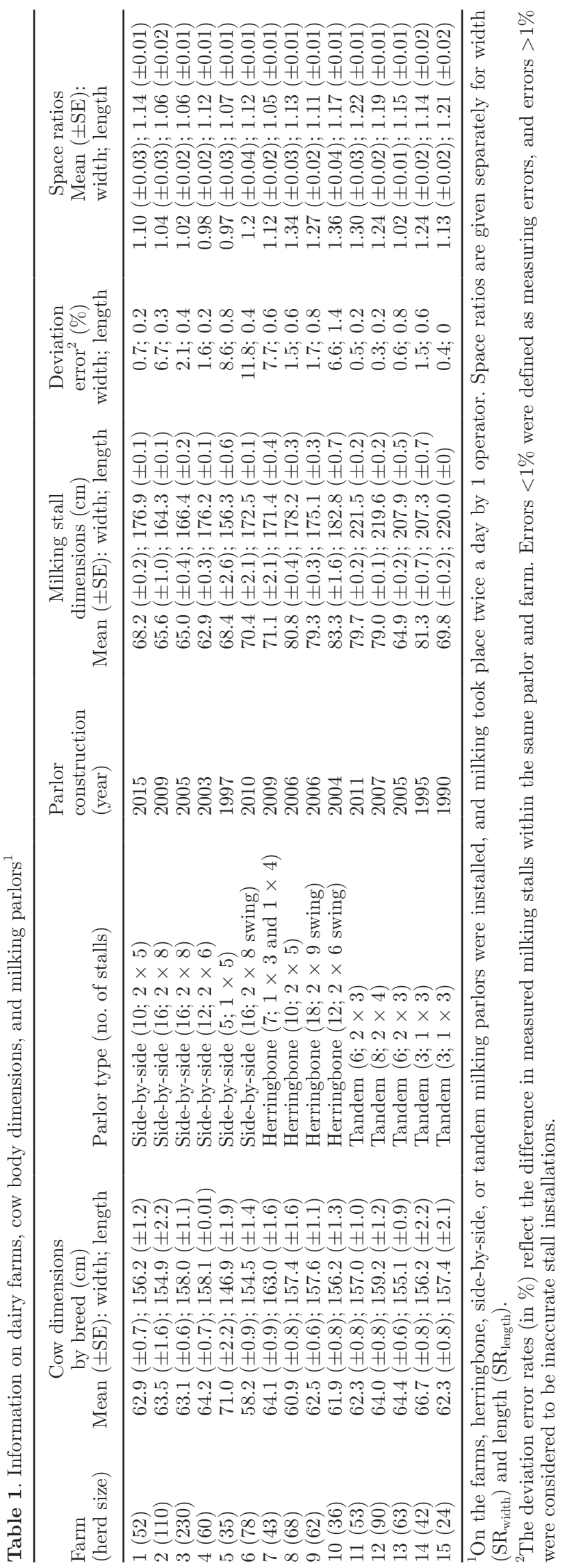


(Table 1): (1) Loose housing system with self-locking feed racks (for technical reasons, see below) and at least 1 of the main breeds (Brown Swiss, Red or Black Holstein, or both); (2) Cows dehorned or genetically hornless; (3) More than 10 cows in lactation; (4) Ceiling height of at least $4 \mathrm{~m}$ close to the feed racks (necessary for measuring body dimensions, see below); (5) Permission from the farmer to select and mark 10 healthy cows of the main breeds to get a balanced design for analysis, and to equip them with accelerometer devices on the hind legs; (6) Common herringbone, side-by-side, or (auto-) tandem milking parlor; (7) Milking twice a day by only 1 operator.

We based selection of cows for direct observation on good health condition (no lameness and no udder infections) as indicated by the farmers and took place when cows were locked in the feed racks for photography. On farms with more than 1 breed, we selected the same number of cows per breed. During selection, we had no information on cows' parity or stage of lactation.
Our aim had been to measure all cows on each farm, but sometimes, some cows were housed in areas with a ceiling height that was too low to measure body dimensions from above.

\section{Measuring Dimensions of Milking Stalls and Cows}

On each farm, we measured stall dimensions in the parlor using meter and Leica Disto X310 devices (Leica Geosystems AG, Heerbrugg, Switzerland). We measured only clear widths and lengths, because these were relevant for the space available to cows.

In Figure 1, the length and width of milking stalls are marked for the 3 milking parlor types considered in our study (common herringbone, side-by-side, and tandem). We measured the dimensions of all milking stalls in each milking parlor. For stall width and length, we calculated the mean per farm. For stall width, the deviations within parlors were high and were due to inaccurate milking stall installation rather than to (a)

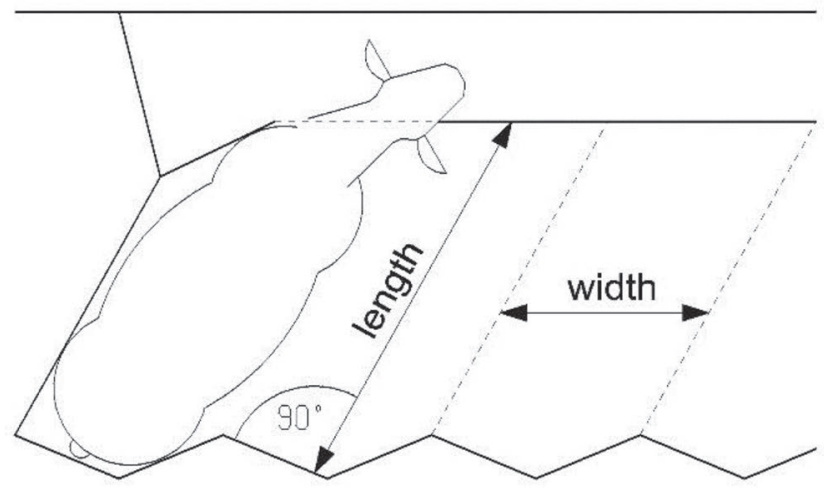

(b)

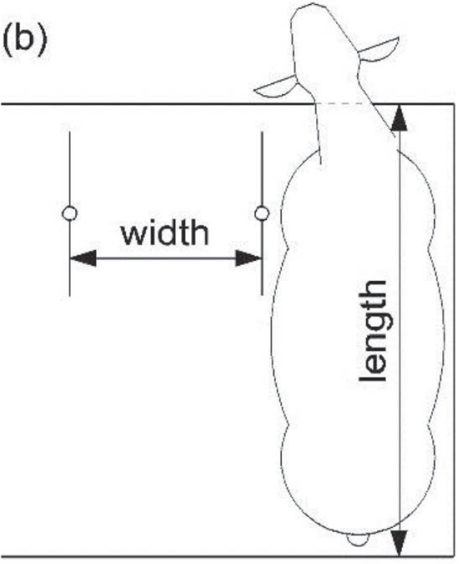

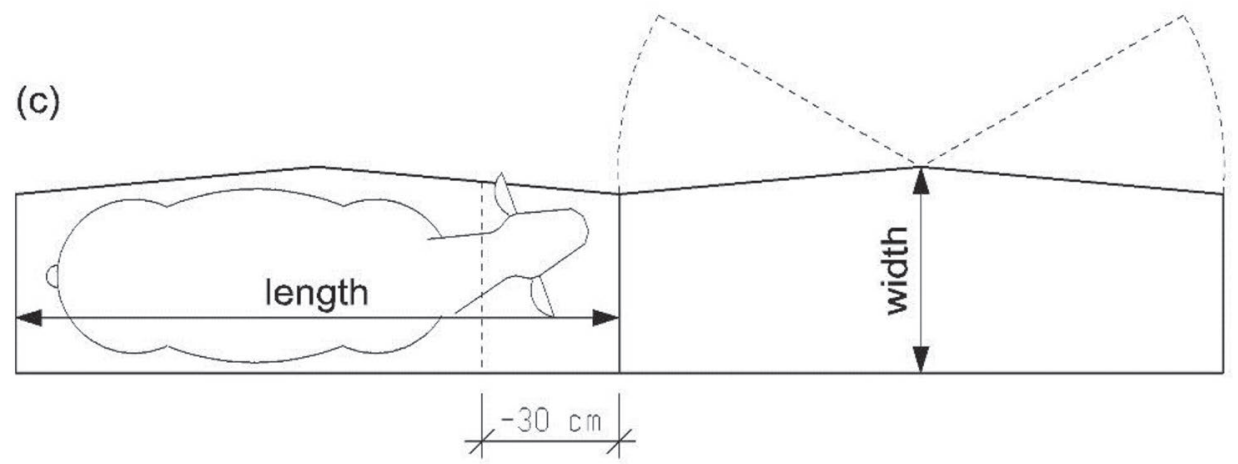

Figure 1. Clear width and length measurements of milking stall dimensions for the milking parlor types: (a) herringbone, (b) side-by-side, and $(\mathrm{c})$ tandem. 
measuring errors (deviation error rates $>1 \%$; Table 1 ); for milking stall length, average deviation error rates were $<1 \%$. In tandem parlors, feed dispensers reduced the space for cows. Therefore, we subtracted the length of the feed dispenser (diameter of $30 \mathrm{~cm}$; black, dashed line in Figure 1) from the length of the stall so that the space allowance for cows was comparable across parlor types.

Until now, stall length has been measured rectangularly from breast rail to rump rail in herringbone parlors, but this did not reflect the actual length cows experienced, so we measured the diagonal length rather than the rectangular length.

To measure cow body dimensions, we used a camera system with a digital single-lens reflex camera (Figure 2a, label 1; Nikon D7000 with a Nikon AF Nikkor 24 mm f/2.8 D prime lens; Nikon, Melville, NY), attached to a mobile tall tripod (Figure 2a, label 2) connected to a laptop (Figure 2a, label 3) to trigger pictures using the software Lightroom 5 (Adobe Systems Inc., San Jose, CA). This method allowed for rapid collection of data without the need to handle and to touch the cows. Pictures were taken from above with a red reference plate $(15 \times 15 \mathrm{~cm})$ at backbone height (Figure $2 \mathrm{a}$, label 4) during 1 morning feeding. We analyzed the images using ImageJ 1.48v (Rasband, W.S., ImageJ, US National Institutes of Health, Bethesda, MD), which is used to measure tissue, bones, or morphometrics (Abràmoff et al., 2004; Doube et al., 2010; Schneider et al., 2012). Using the reference plate, we calibrated the

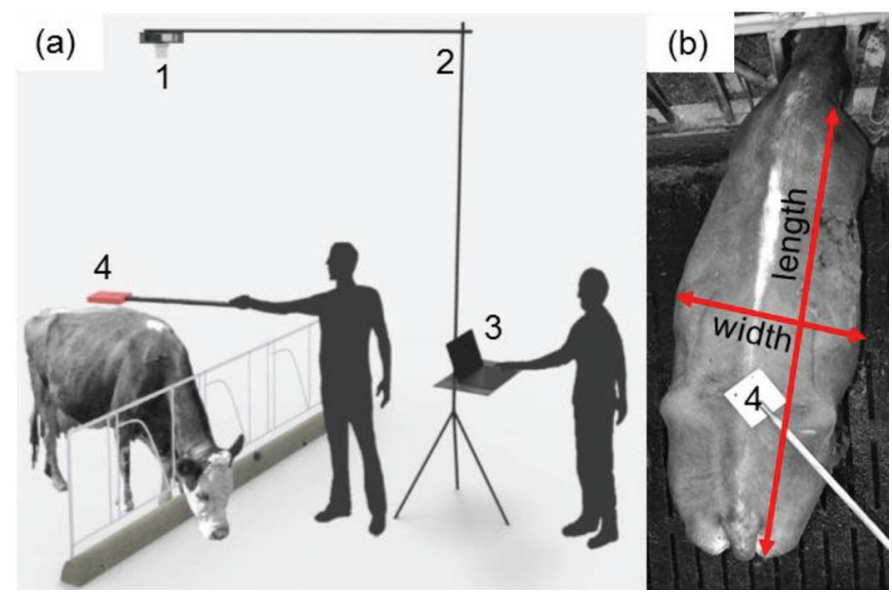

Figure 2. (a) Camera-system installation to measure cows from above without the need for direct handling. The camera (1; Nikon D7000, Nikkor 24mm f/2.88 D prime lens; Melville, NY) was fixed on a mobile tall tripod (2) and connected to a laptop (3) to trigger pictures when the reference plate $(4 ; 15 \times 15 \mathrm{~cm})$ was at the cow's backbone height. (b) Based on the area and length of the reference plate, the pixel scale was calibrated using ImageJ software (US National Institutes of Health, Bethesda, MD) to measure cow body length and belly width. Color version available online. measurement tool and measured the body lengths and belly widths of the cows (Figure $2 \mathrm{~b}$ ). Body length was from the head of the humerus (caput humeri, defined as the cranial boundary for shoulders) to the caudal ischial tuberosity at the pin bones (os ischii). Belly width was the largest width at the belly, viewed from above. According to some pretesting, belly width was not affected by gut filling before or after feeding. Nevertheless, pictures were always taken during feedings.

\section{Definition and Calculation of Space Ratios}

To obtain a comparable unit for the spatial conditions of individual cows, we calculated space ratios separately for length $\left(\mathbf{S R}_{\text {length }}\right)$ and width $\left(\mathbf{S R}_{\text {width }}\right)$, dividing milking stall dimension by cow dimension (Eq. [1] and [2]):

$$
\begin{aligned}
\mathrm{SR}_{\text {width }}= & \text { clear width of milking stall }(\mathrm{cm}) / \\
& \text { belly width of cow }(\mathrm{cm}) \\
\mathrm{SR}_{\text {length }}= & \text { clear length of milking stall }(\mathrm{cm}) / \\
& \text { body length of cow }(\mathrm{cm}) .
\end{aligned}
$$

For statistical analysis, we calculated space ratios individually for all cows based on the average milking stall dimension found on their farm. An $\mathrm{SR}_{\text {length }}>1$ meant that the milking stall was longer than the cow; a space ratio $<1$ meant that it was too short or too narrow for the cow.

\section{Behavioral Parameters}

All direct observations of cows took place during evening milking only, once per farm, with 1 observer collecting data. The order of farms and parlor type was random. The observer was trained for behavioral observation and conducted all direct observations while standing in the milking pit without influencing the milking routine. Across farms, a maximum of 2 focus cows were in the parlor at the same time but never on the same parlor side. The exact milking time for each focus cow was recorded using a stopwatch, starting with attachment of the milking cluster and ending with detachment of the cluster, when the automatic cluster remover indicated removal with a visual signal or the milker indicated intention to remove it. To observe rumination in group milking parlors, the observer bent down to see cows' heads more clearly. Focus cows were recognizable because of the colored bandages on their hind legs.

Rumination. As soon as the cow entered the milking stall, she was observed for rumination activity. 
Rumination was recorded at 4 points: before cluster attachment, 2 times during milking (approximately 3 and 6 min after cluster attachment), and shortly before detachment of clusters, as described earlier. At these 4 time points, constant chewing of cud for $>30 \mathrm{~s}$ was defined as rumination activity. Rumination was recorded when the cow was ruminating during at least 2 of these 4 time points.

Elimination. From entering the milking stall until leaving, cows were directly observed for urination and defecation. We recorded the events per milking and per cow. Defecation and urination were combined as elimination events because of their rare occurrence during this study.

Hind Leg Activity and Maximum Peaks of 3D-Accelerations. To record hind leg activity during milking, we attached a 3D-acceleration logger (MSR145; MSR Electronics GmbH, Seuzach, Switzerland) with a recording rate of $1 \mathrm{~Hz}$ (1 data point per second) and a sensor sensitivity of $2 \mathrm{~g}$ to the left hind leg above the fetlock (articulatio metatarsophalangea) by using a colored bandage with hook-and-loop fasteners. The loggers were set to collect data continuously during the milking period. After the device was attached, cows were allowed to habituate for approximately 4 to $5 \mathrm{~h}$ before measurements began. After measurements were taken, the device was removed and data were transmitted to the computer using MSR 5.24.02v (MSR Electronics $\mathrm{GmbH}$ ). To analyze acceleration measures, we considered only the data collected by the logger within cows' individual milking start and end times (as described earlier). We summed the absolute values of all 3 dimensions and divided them by milking duration (in s) to calculate an activity rate, comparable across cows and farms. We also extracted maximum peaks (highest value of the summed 3 dimensions per s) of hind leg accelerations per milking and per cow as an approximation of hind leg lifting/kicking and used them as an indicator of reduced cow comfort. Due to the loss of 2 MSR accelerometer devices, hind leg activity data were available for 148 cows.

Latency to Enter the Milking Stall. Latency to enter the milking stall was defined as the directly observed time period from when the focus cow crossed a virtual borderline at the entrance of the parlor gate with both front legs until the moment the cow was standing with all 4 legs at the corresponding milking position.

\section{Statistical Analysis}

We analyzed the data using linear mixed-effects models in R 3.1.0 (R Core Team, 2015) using LME4 (Bates et al., 2014). Because there was a significant correla- tion between the log-transformed $\mathrm{SR}_{\text {length }}$ and $\mathrm{SR}_{\text {width }}$ with correction for farms $\left(\mathrm{R}^{2}=0.57, P<0.0001\right)$, we used only $\mathrm{SR}_{\text {length }}$ for the final models, because body length is defined by the skeleton, and belly width may be influenced by stage of pregnancy. For group milking parlors in particular, space allowance for belly width depends not only on a cow's individual belly width but also on the belly widths of neighboring cows.

Parity and stage of lactation were not included in the model, because milking stalls are designed the same way for all cows on a farm, regardless of parity or stage of lactation. However, both variables were evenly distributed across farms and parlor types, ensuring no bias in the data.

The full model had the following structure (Eq. [3]):

$$
y=C+\left[\log \left(\mathrm{SR}_{\text {length }}\right)+T i\right]^{j}+B i,
$$

with $y$ representing the outcome variable [continuous for hind leg activity rates, maximum peaks of hind leg accelerations and latency to enter the milking stall, or binomial for elimination and rumination (yes/no)]. To achieve normally distributed residuals, $y$ was $\log$ transformed for hind leg activity rate, maximum peaks of accelerations, and latency to enter the milking stall. $C$ represented a constant, $\mathrm{SR}_{\text {length }}$ was the calculated space ratio length, $T$ was the milking parlor type [common herringbone $(i=1)$; side-by-side $(i=2)$; tandem $(i=3)]$ and $B$ was the breed [Brown Swiss $(i=1)$; Red or Black Holstein $(i=2)$ ] used as a controlling covariable for breed-specific behavioral effects. The term $(.)^{j}$ indicated analysis of the effects of first-degree $(j=2)$ interaction of the 2 factors $\mathrm{SR}_{\text {length }}$ and $T$. Farm was a random effect to account for the nested data structure.

The effect of parlor type on $\mathrm{SR}_{\text {length }}$ was analyzed using the following model (Eq. 4):

$$
y=C+T i
$$

with $y$ representing the log-transformed $\mathrm{SR}_{\text {length }}, C$ a constant, and $T$ the type of milking parlor [common herringbone $(i=1)$; side-by-side $(i=2)$; tandem $(i=$ $3)]$. Farm was a random effect to account for the nested data structure.

For rumination and elimination, we calculated odds ratios for the $\mathrm{SR}_{\text {length }}$ and milking parlor type, if $P<$ 0.1 . For the statistical analyses, we selected the final model using a stepwise backward elimination procedure of nonsignificant $(\alpha \geq 0.05)$ fixed effects. The $\mathrm{SR}_{\text {length }}$ and milking parlor type were always included in the final model as main effects. We applied Tukey post hoc tests for significant effects using the MULTCOMP (Hothorn et al., 2008). Results are shown as boxplots 
with median, interquartiles, and range plus model estimates and $95 \%$ confidence interval.

\section{RESULTS}

\section{Milking Stall and Cow Body Dimensions}

Across farms, milking stall length ranged from 156.3 $\mathrm{cm}$ to $221.5 \mathrm{~cm}$ and stall width from $59.5 \mathrm{~cm}$ to 83.3 $\mathrm{cm}$, depending on the milking parlor type (Table 1).

In total, we measured 444 cow body dimensions on the 15 farms. Body lengths ranged from $146.9 \mathrm{~cm}$ to $163.1 \mathrm{~cm}$, and belly widths from $60.9 \mathrm{~cm}$ to $71.0 \mathrm{~cm}$ across all breeds and farms (Table 1). On average, Red and Black Holsteins had the widest bellies, but body length was similar for Brown Swiss and Red and Black Holstein cows.

\section{Space Ratio}

We calculated average space ratios: $\mathrm{SR}_{\text {width }}$ ranged from 0.86 to 1.62 , and $\mathrm{SR}_{\text {length }}$ ranged from 0.96 to 1.38 . They varied within type of milking parlor and farm due to difference in milking stall widths and variations be-

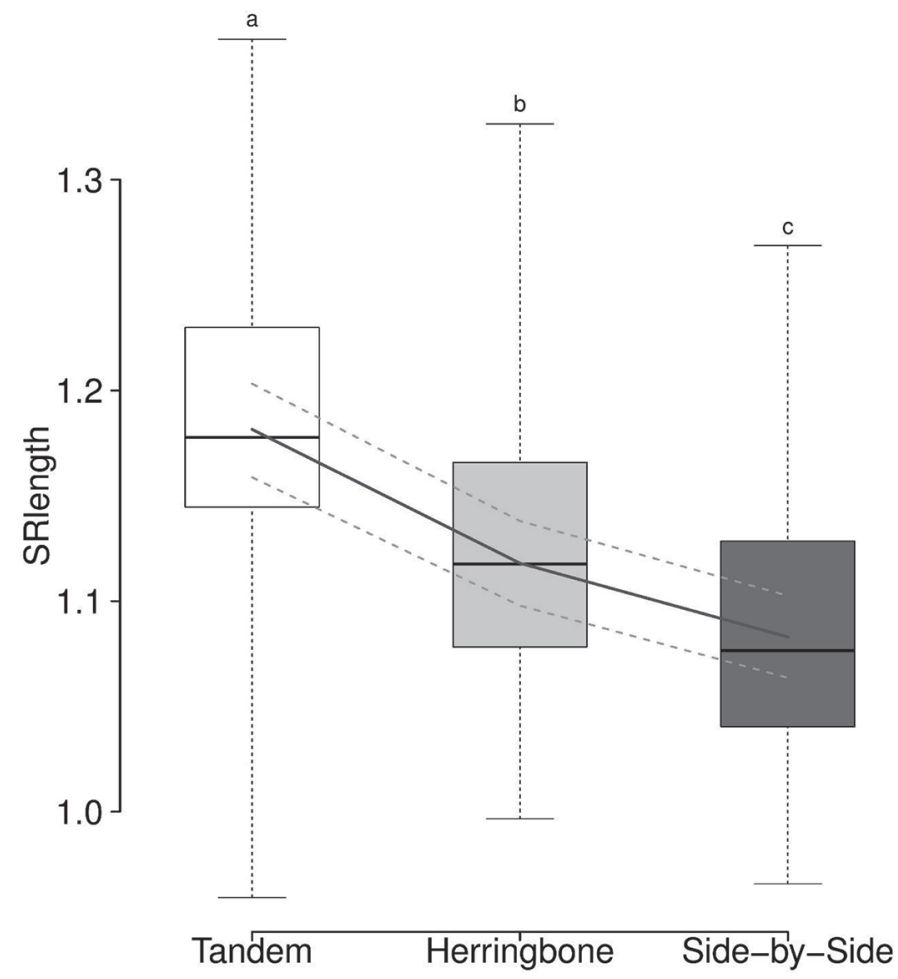

Figure 3. Space ratio length $\left(\mathrm{SR}_{\text {length }}\right)$ in the milking parlor types studied. Solid line $=$ model estimate; dashed lines $=95 \%$ upper and lower confidence intervals of model estimate. Different letters indicate significant differences based on Tukey post hoc comparisons ( $P$ $<0.05)$. tween cows (Table 1 ). The $\mathrm{SR}_{\text {length }}$ was larger in tandem parlors than in group milking parlors $(P<0.024)$. Herringbone parlors had larger $\mathrm{SR}_{\text {length }}$ than side-by-side parlors $(P=0.0233)$, but smaller $\mathrm{SR}_{\text {length }}$ than tandem parlors $(P<0.0001)$ (Figure 3$)$.

\section{Behavioral Parameters}

Rumination. In total, $41 \%$ of cows showed rumination during milking. With increasing $\mathrm{SR}_{\text {length, }}$ the probability of more cows ruminating during milking tended to increase (Figure $4 ; \chi^{2}=3.253$, df $=1, P=0.071$, $\left.\mathrm{OR}_{\text {SRlength }}=1.8\right)$. We found no significant effect of parlor type on rumination $\left(\chi^{2}=4.301, \mathrm{df}=2, P=0.116\right)$.

Elimination. Because of the rare occurrence of elimination, with no events recorded for tandem parlors, 3 for herringbone parlors, and 9 for side-by-side parlors, we conducted no analysis.

Hind Leg Activity Rate and Maximum Peaks of $3 \boldsymbol{D}$-Accelerations. We observed no significant effects of $\mathrm{SR}_{\text {length }}$ and milking parlor on hind leg activity rate $\left(1.23 \pm 0.01 \mathrm{~g} / \mathrm{min} ; \mathrm{SR}_{\text {length }}: F_{1,62}=0.735, P=\right.$ 0.395; milking parlor: $\left.F_{2,14}=0.575, P=0.576\right)$, or on maximum peaks of hind leg accelerations $(2.39 \pm 0.09$ $\mathrm{m} / \mathrm{s}^{2} ; \mathrm{SR}_{\text {length }}: F_{1,92}=1.210, P=0.274 ;$ milking parlor: $\left.F_{2,17}=2.269, P=0.135\right)$.

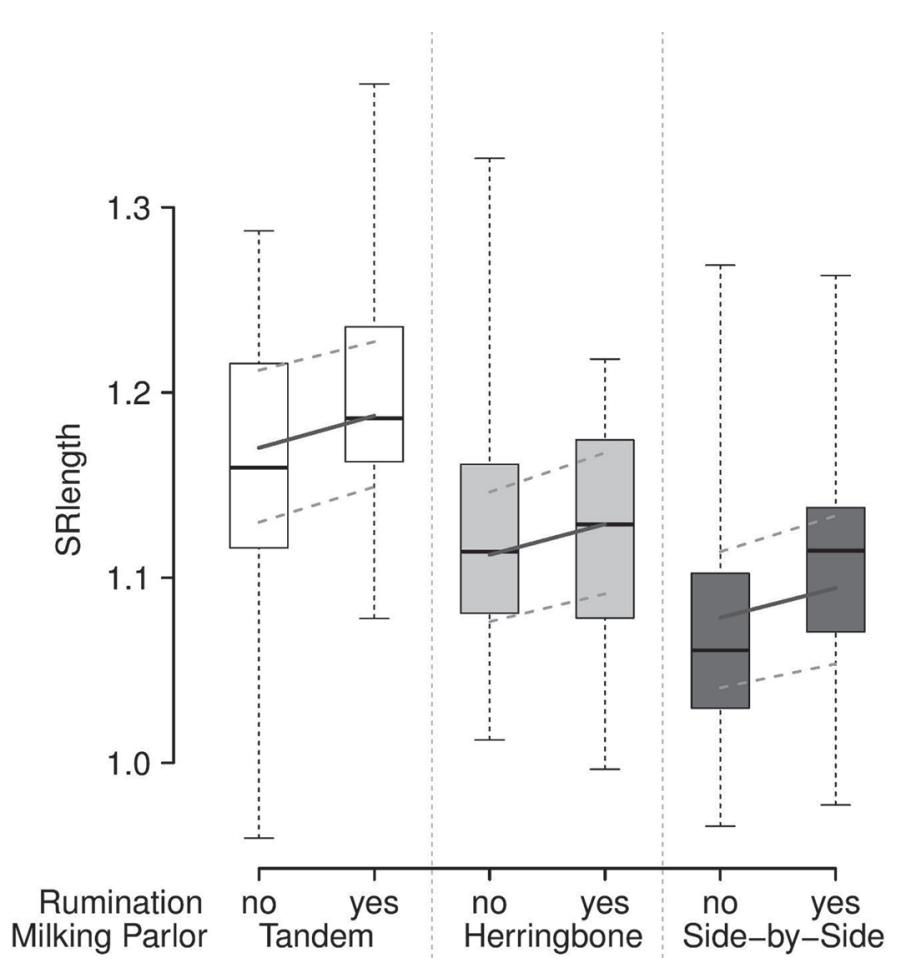

Figure 4. Occurrence of rumination (yes/no) in relation to space ratio length $\left(\mathrm{SR}_{\text {length }}\right)$ and parlor type. Solid line = model estimate, dashed lines $=95 \%$ upper and lower confidence intervals of model estimate. 
Latency to Enter the Milking Stall. Latency to enter the milking stall was longer for herringbone $(34.3 \pm 2.9 \mathrm{~s})$ and side-by-side $(44.0 \pm 3.2 \mathrm{~s})$ than for tandem parlors $(19.0 \pm 2.7 \mathrm{~s} ; P<0.0001$, Figure 5$)$. We observed no significant difference between side-byside and herringbone parlors $(P=0.175)$. Furthermore, $\mathrm{SR}_{\text {length }}$ did not affect latency to enter the milking stall $\left(\mathrm{SR}_{\text {length }}: F_{1,130}=0.382, P=0.538\right)$.

\section{DISCUSSION}

$\mathrm{SR}_{\text {length }}$ was largest in tandem parlors and smallest in side-by-side, with herringbone showing intermediate $\mathrm{SR}_{\text {length }}$ values. The larger the $\mathrm{SR}_{\text {length }}$, the more cows tended to ruminate, independent of parlor type. Furthermore, latency to enter the milking stall was longer in group milking parlors than in tandem parlors, irrespective of $\mathrm{SR}_{\text {length. }}$

Altogether, we did not find effects of $\mathrm{SR}_{\text {length }}$ that would indicate severely reduced welfare during milking (Hopster et al., 1998; Stefanowska et al., 2000; Rushen et al., 2001; Hagen et al., 2004). On most farms, milking stalls were longer than the cows (i.e., cows should have been able to stand in the milking stall without touching the rails when standing still). However, the increased probability of ruminating with longer stall length would imply that a larger $\mathrm{SR}_{\text {ength }}$ positively affects the well-being of cows during milking, likely because cows are more relaxed. Unfortunately, no studies are available that investigate rumination activity during milking (i.e., how many cows and how long they ruminate during milking). Nevertheless, previous studies (not conducted during milking) found that rumination activity decreased and cortisol levels increased when cows were exposed to stressful situations (Fisher et al., 1997; Herskin et al., 2004; Bristow and Holmes, 2007). Thus, our study provided hints of higher cow comfort with larger milking stalls. All cows saw the foreign observer, who was standing in the milking pit. This might have influenced rumination, leading to less activity than without an observer, because of exposure toward an unpredictable situation (Herskin et al., 2004). However, this effect was given in all parlor types. The extent to which space allowance affects milk let-down (e.g., milk yield, milk flow curves) remains to be investigated.

In general, cows eliminate more in stressful situations (i.e., fear, novel situations, high arousal; Stefanowska et al., 2000; Rushen et al., 2001; Hagen et al., 2004; Hoy, 2009). Because of the rare occurrence of elimination in our study, we could not apply statistical analyses, but we found elimination events only in group milking parlors.

We could not find significant effects of space allowance on hind leg activity as an indication of stress during

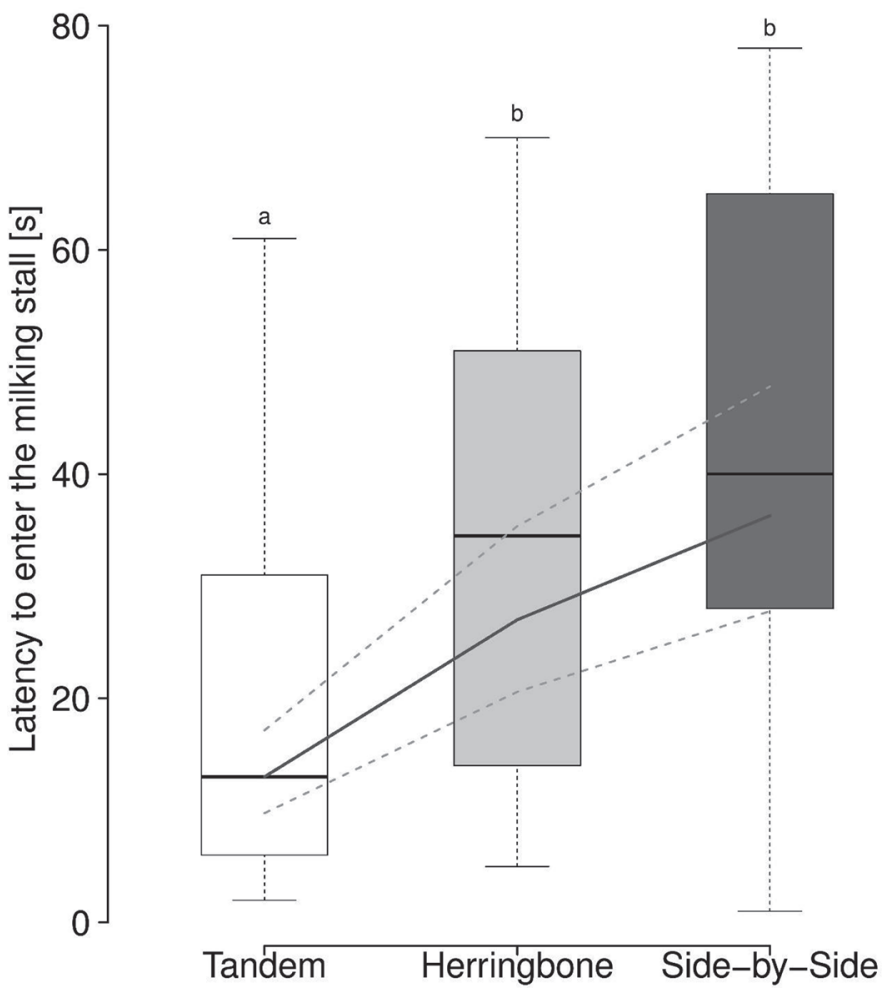

Figure 5. Latency to enter the milking stall in relation to milking parlor type. Solid line $=$ model estimate, dashed lines $=$ upper and lower $95 \%$ confidence intervals of model estimate. Different letters indicate significant differences based on Tukey post hoc comparisons $(P<0.05)$

milking. The reason for this might be that in our study $\mathrm{SR}_{\text {length }}$ was $>1$ on most farms. Furthermore, hind leg activity rates showed high variation across farms and within farms, as found by Rousing et al. (2004). These high variations might have masked potential parlor or space ratio effects in our study. Several studies used kicking and stepping as behavioral indicators of stress responses to milking conditions (Wenzel et al., 2003; Rousing et al., 2004; Gygax et al., 2007). We did not directly measure kicking and stepping, choosing instead overall hind leg activity and maximum peaks within hind leg activity. The continuous data collection using accelerometer devices was a standardized method with no activity to be missed, whereas kicking and stepping was defined differently across previous studies.

In this study, latency to enter the milking stall was not significantly affected by $\mathrm{SR}_{\text {length. }}$. It was, however, affected by milking parlor type. One reason might be the influence of neighboring cows in group milking parlors compared with tandem parlors, making latency to enter the stall dependent not only on the focus cow but also on the behavior of the cow in the front or the back. Furthermore, with positive animal-human rela- 
tionships, cows that see the milker would more likely be motivated to enter. Additionally, the longer latency in side-by-side than in herringbone parlors might be because of the steeper entrance angle of $90^{\circ}$ in the former. Reduced cow comfort during milking might also result in avoidance behavior and an increased latency to enter. Besides space allowance, management factors such as feeding (Hopster et al., 1998; Ceballos and Weary, 2002) and human-animal relationship (Waiblinger et al., 2006) may affect the willingness of a cow to enter the milking stall or milking parlor in ways that we did not control for in our study.

In general, results concerning latency cannot be fully compared across parlors because of differences in distance between the entrance of the parlor and the milking stall itself. In our study, cows were allowed to enter the milking parlor with free choice of side and milking position. This distance might also have affected latency to some extent and needs better consideration in future studies by correcting for latency using the actual distance covered by cows.

For cow body dimensions, we measured body length from the caput humeri to ischium point, as these edges reflected the main contact points between cow and milking stall, in particular for group milking parlors and for tandem parlors using feed dispensers. Measuring this way allowed exact comparison between cow body length and milking stall length.

The differences in $\mathrm{SR}_{\text {length }}$ between the milking parlor types reflected installation differences to some extent. In side-by-side parlors, milkers attach milking clusters through the cow's hind legs, which requires a shorter $\mathrm{SR}_{\text {length }}$ to ensure close proximity between udder and milker. Furthermore, the breast barrier in side-by-side parlors closes from top and bottom, whereas in herringbone parlors the breast barriers are close to cows' throat, so more space is needed to prevent pressure on the throat by the barrier. This difference might explain the smaller $\mathrm{SR}_{\text {length }}$ values for side-by-side than for herringbone parlors.

In tandem parlors, cows are milked from the side, with every cow standing in a single box. The feed dispenser reduced the space for cows by $30 \mathrm{~cm}$. Therefore, tandem stall length did not fully reflect the stall length cows experience as anatomical limitations in group milking parlors, because the length from the caput humeri to the nose tip is longer than the $30 \mathrm{~cm}$ subtracted. However, it was not possible to measure this distance precisely and accurately. In the 1930s, neck length was on average $49.75 \mathrm{~cm}$ for Brown Swiss (with high variance $\pm 3.33 \mathrm{~cm}$, or $6.7 \%$; Sciuchetti, 1933). This neck length might have changed with time, because cows in the 1930s had a height at withers of only $134.3 \mathrm{~cm}$ (Sciuchetti, 1933). Therefore, although $\mathrm{SR}_{\text {length }}$ was significantly larger for tandem than for group milking parlors, we cannot conclude that cows fit well from nose tip to ischium points in parlors with space ratios $>1$, because $\mathrm{SR}_{\text {length }}$ was calculated excluding the neck-head length.

Although the space ratio was $\geq 1$ in most milking parlors on the analyzed farms, we found some indications of limited space allowance that could reduce cow comfort. This might raise the question whether cows need additional buffer space in milking stalls to be fully relaxed during milking, irrespective of milking parlor type. We observed cows curving their backs by shifting their hind legs far below their rump in side-by-side milking parlors, in particular. In herringbone milking parlors, many cows bowed their necks or lifted their heads, although the space ratio in most cases equaled 1. These observations indicated the importance of buffer space between cow and rails in milking stalls to improve cow comfort. Further investigations will help to determine $\mathrm{SR}_{\text {lengths }}$ that ensure appropriate buffer space in milking stalls for higher cow comfort (no curved back, no bowed neck or tucked-in tail) during milking.

\section{ACKNOWLEDGMENTS}

Special thanks go to all dairy farms that participated in this study; Markus Keller and Martin Schlatter (both of Agroscope Tänikon) for their technical support during cow measurement on farms; and Daniel Herzog (Agroscope Tänikon) and Milena Terranova for designing Figures 1 and 2. We are grateful for the helpful comments of 2 anonymous reviewers. This project was financed by the Swiss Federal Food Safety and Veterinary Office (Project No. 2.12.05).

\section{REFERENCES}

Abràmoff, M. D., P. J. Magelhães, and S. J. Ram. 2004. Image processing with ImageJ. Biophoton. Int. 11:36-42.

Bates, D., M. Maechler, B. Bolker, and S. Walker. 2014. lme4: Linear mixed-effects models using Eigen and S4. J. Stat. Softw. 67:1-48.

Brade, W., and E. Brade. 2013. Zuchtgeschichte der Deutschen Holsteinrinder. Berichte über Landwirtschaft 91:1-41. [In German]

Bristow, D. J., and D. S. Holmes. 2007. Cortisol levels and anxietyrelated behaviors in cattle. Physiol. Behav. 90:626-628.

Ceballos, A., and D. M. Weary. 2002. Feeding small quantities of grain in the parlour facilitates pre-milking handling of dairy cows. A note. Appl. Anim. Behav. Sci. 87:2042-2050.

Cockburn, M., P. Savary, M. Kauke, M. Schick, U. Hoehne-Hückstädt, I. Hermanns, and R. Ellegast. 2015. Improving ergonomics in milking parlors: Empirical findings for optimal working heights in five milking parlor types. J. Dairy Sci. 98:966-974.

Defra (Department for Environment, Food and Rural Affairs (Defra), London, UK). 2003. Caring for beef cattle and dairy cows. Accessed Nov. 15, 2016. https://www.gov.uk/government/publications/ code-of-recommendations-for-the-welfare-of-livestock-cattle/beefcattle-and-dairy-cows-welfare-recommendations.

Doube, M., M. M. Klosowski, I. Arganda-Carreras, F. P. Cordelières, R. P. Dougherty, J. S. Jackson, B. Schmid, J. R. Hutchinson, and 
S. J. Shefelbine. 2010. BoneJ: Free and extensible bone image analysis in ImageJ. Bone 47:1076-1079.

Douphrate, D. I., C. Lunner Kolstrup, M. W. Nonnenmann, M. Jakob, and S. Pinzke. 2013. Ergonomics in modern dairy practice: A review of current issues and research needs. J. Agromedicine 18:198-209.

Eilers, U. 2007. Liegeboxenmasse: Kompromissformel für Komfort. Bildungs-und Wissenszentrum Aulendorf-Viehaltung, Grünlandwirtschaft, Wild, Fischerei, Germany. [In German]

Fernández, M. E., R. A. Marino, and X. C. Carreira. 2009. Algorithms for dairy barn design: Maternity and milking areas. J. Dairy Sci. 92:2276-2296.

Fisher, A. D., M. A. Crowe, D. J. Prendiville, and W. J. Enright. 1997. Indoor space allowance: Effects on growth, behaviour, adrenal and immune responses of finishing beef heifers. Anim. Sci. 64:53-62.

Flaba, J., J. Owen, H. Bartussek, U. Chiappini, H. Pirkelmann, and M. Smits. 2004. Design Recommendations of Beef Cattle Housing. CIGR, East Lansing, MI.

Grothe, P. O. 2007. Holstein-Schauen im Wandel der Zeit. Land und Forst 22:35-37. [In German]

Gygax, L., I. Neuffer, C. Kaufmann, R. Hauser, and B. Wechsler. 2007. Restlessness behaviour, heart rate and heart-rate variability of dairy cows milked in two types of automatic milking systems and auto-tandem milking parlours. Appl. Anim. Behav. Sci. 109:167-179

Hagen, K., D. Lexer, R. Palme, J. Troxler, and S. Waiblinger. 2004. Milking of Brown Swiss and Austrian Simmental cows in a herringbone parlour or an automatic milking unit. Appl. Anim. Behav. Sci. 88:209-225.

Herskin, M. S., L. Munksgaard, and J. Ladewig. 2004. Effects of acute stressors on nociception, adrenocortical responses and behavior of dairy cows. Physiol. Behav. 83:411-420.

Hopster, H., J. T. N. van der Werf, and H. J. Blokhuis. 1998. Side preference of dairy cows in the milking parlour and its effects on behaviour and heart rate during milking. Appl. Anim. Behav. Sci. 55:213-229.

Hothorn, T., F. Bretz, and P. Westfall. 2008. Simultaneous inference in general parametric models. Biom. J. 50:346-363.

Hoy, S. 2009. Nutztierethologie. Verlag Eugen Ulmer KG, Stuttgart (Hohenheim), Germany. [In German]

Irrgang, N., K. A. Zipp, S. Brandt, and U. Knierim. 2015. Effects of space allowance in the waiting area on agonistic interactions and heart rate of high and low ranking horned dairy cows. Livest. Sci. 179:47-53.

Nordlund, K., and N. Cook. 2003. A flowchart for evaluating dairy cow freestalls. Bov. Pract. 37:89-96.

O'Brien, B., J. Jago, J. P. Edwards, N. Lopez-Villalobos, and F. McCoy. 2012. Milking parlour size, pre-milking routine and stage of lactation affect efficiency of milking in single-operator herringbone parlours. J. Dairy Res. 79:216-223.

Petermann, R. 2005. Development of Milk Yield and Withers Height (WH) of Swiss Dairy Breeds (1992-2003). Berufsbildungszentrum-Natur und Ernährung, Schüpfheim, Switzerland.
R Core Team. 2015. R: A Language and Environment for Statistical Computing. R Foundation for Statistical Computing, Vienna, Austria.

Rauw, W. M., E. Kanis, E. N. Noordhuizen-Stassen, and F. J. Grommers. 1998. Undesirable side effects of selection for high production efficiency in farm animals: A review. Livest. Prod. Sci. 56:15-33.

Rodenburg, T. B., and S. P. Turner. 2012. The role of breeding and genetics in the welfare of farm animals. Anim. Front. 2:16-21.

Rousing, T., M. Bonde, J. H. Badsberg, and J. T. Sorensen. 2004 Stepping and kicking behaviour during milking in relation to response in human-animal interaction test and clinical health in loose housed dairy cows. Livest. Prod. Sci. 88:1-8.

Rudolphi, B. 2008. Klasse statt Masse - Zusammenhänge von Grösse, Gewicht und Leistungen bei Milchkühen. 26. Tag des Milchviehalters. Sachsen-Anhalt, Germany. [In German]

Rushen, J., L. Munksgaard, P. G. Marnet, and A. M. DePassillé. 2001. Human contact and the effects of acute stress on cows at milking. Appl. Anim. Behav. Sci. 73:1-14.

Savary, P., O. Weber, and Th. Richter. 2014. Ethologische Untersuchungen im Melkstand - ein Vergleich zwischen Gruppen- und Einzelmelkständen. Pages 184-191 in Aktuelle Arbeiten zur artgemässen Tierhaltung, 505. KTBL, Darmstadt, German. [In German]

Schneider, C. A., W. S. Rasband, and K. W. Eliceiri. 2012. NIH Image to ImageJ: 25 years of image analysis. Nat. Methods 9:671-675.

Schönmuth, G., and M. Löber. 2006. Beziehungen zwischen Körpergrösse und Leistungen beim Rind. Zuchtungskunde 78:324-335.

Sciuchetti, A. 1933. Der derzeitige weibliche Zuchttypus des schweizerischen Braunviehes, dargestellt mittels der Körpermasse und der Lebensgewichte von ausgesprochenen Rassetieren. PhD Thesis. Diss. ETH No. 751 B. Verlag Paul Parey, Berlin, Germany. [In German]

Smith, J. F., D. V. Armstrong, M. J. Gamroth, and J. G. Martin. 1997. Planning the milking center in expanding dairies. J. Dairy Sci. 80:1866-1871.

Stefanowska, J., M. Plavsic, A. H. Ipema, and M. M. W. B. Hendriks. 2000. The effect of omitted milking on the behaviour of cows in the context of cluster attachment failure during automatic milking. Appl. Anim. Behav. Sci. 67:277-291.

Tranel, L., L. Sternweis, J. Lenahan, and J. Harmon. 2007. Developing dairy in Iowa: Transforming a milking parlor at low cost. Iowa State University Extensions. PM 2033. Accessed Nov. 15, 2016. http://dev-02.exnet.iastate.edu/store/Product/12657

Waiblinger, S., X. Boivin, V. Pedersen, M.-V. Tosi, A. M. Janczak, E. K. Visser, and R. B. Jones. 2006. Assessing the human-animal relationship in farmed species: A critical review. Appl. Anim. Behav. Sci. 101:185-242

Wechsler, B. 2005. An authorisation procedure for mass-produced farm animal housing systems with regard to animal welfare. Livest. Prod. Sci. 94:71-79.

Wenzel, C., S. Schonreiter-Fischer, and J. Unshelm. 2003. Studies on step-kick behavior and stress of cows during milking in an automatic milking system. Livest. Prod. Sci. 83:237-246. 